\title{
"Step by step": the development of a therapeutic game to assist in the treatment of drug use
}

\author{
"Passo a passo": desenvolvimento de um jogo terapêutico para \\ auxiliar no tratamento do uso de drogas
}

Viviane Peçaibes (https://orcid.org/0000-0002-4198-5972) ${ }^{1}$

Leandro Miletto Tonetto (https://orcid.org/0000-0002-4403-2085) ${ }^{1}$

Ilana Andretta (https://orcid.org/0000-0002-5537-5120) ${ }^{2}$

${ }^{1}$ Programa de PósGraduação em Design, Universidade do Vale do Rio dos Sinos. Av. Nilo Peçanha 1600, Bairro Boa Vista. 91330-002 Porto Alegre RS Brasil.vivianepecaibes@ gmail.com

${ }^{2}$ Programa de PósGraduação em Psicologia, Universidade do Vale do Rio dos Sinos. Porto Alegre RS Brasil.

\begin{abstract}
This research aimed to understand the potential of game design to improve the experience of drug users and their families with psychoeducation. In the design field, the term experience refers to the quality of the interaction between people and a product, which is, in this research, a therapeutic game called "Step by Step". Fifteen in-depth interviews were developed with patients and their family members after playing "Step by Step" in multifamily groups. Results indicate that the game improved the experience with psychoeducation. Participants' appraisals suggested that the game dynamics facilitated users' immersion. The playing situation was assessed as safe to address sensitive issues not normally expressed between patients and their relatives. The visual and tactile designed stimuli were evaluated as learning facilitators. The simplicity of the game was appraised as helpful, allowing the inclusion of distinct generations in collective learning. Results provided insights to foster game design in the health field.
\end{abstract}

Key words Drug Use, Cognitive Therapy, Community Health Services
Resumo A presente pesquisa visou compreender o potencial do design de jogos na qualificação das experiências de pacientes e suas famílias com a psicoeducação. No design, o termo experiência refere-se à qualidade da interação entre as pessoas e um produto, que é, nessa pesquisa, um jogo terapêutico chamado "Passo-a-Passo". Foram realizadas 15 entrevistas em profundidade com pacientes e seus familiares após jogarem "Passo-a -Passo" em grupos multifamiliares. Os resultados indicam que o jogo auxiliou na experiência com a psicoeducação. As avaliações dos participantes sugeriram que a dinâmica do jogo facilitou a imersão dos usuários. A situação de jogo foi percebida como segura para abordar tópicos delicados que normalmente não são expressos entre pacientes e familiares. Os estímulos visuais e táteis foram avaliados como facilitadores do aprendizado. A simplicidade do jogo foi indicada como benéfica, permitindo a inclusão de diferentes geraçães em um aprendizado coletivo. Os resultados oferecem novas ideias para o desenvolvimento de jogos no campo da saúde.

Palavras-chave Uso de Drogas, Terapia Cognitiva, Serviços de Saúde Comunitária 


\section{Introduction}

At a historical perspective, public policies related to the treatment of drug users have gone through substantial change in Brazil, shifting from a model that was centered in hospitalization to out-of-hospital alternatives. The Ordinance GM 224/1992 ${ }^{1}$ has set Psycho-Social Care Centers (Centros de Atenção Psicossocial - CAPS) as a new model to assist in the treatment of these patients.

The Federal Law 10.216/2001 ${ }^{2}$ has stablished the constitutional principle of equality to drug users, as it once was applied only to those who were in psychological suffering or were diagnosed with mental health issues. This change has led Brazil to offer public health assistance to these users, invest in the implementation of CAPS and in actions to harm reduction, and allow CAPS to assist these users in their treatment. From that point on, some treatment models are in use, and the relapse prevention is one of them ${ }^{3,4}$.

Relapse prevention is one of the models employed to treat drug use in Brazil. It aims at identifying internal issues of the user, such as emotional assets and personal beliefs, and external matters, such as the patient's environment and family structure. It also targets the learning process of abilities to deal with lapses and relapse episodes, and life-style changes, if necessary. Professionals that adopt this model may employ diverse strategies, such as psychoeducation ${ }^{5}$.

Psychoeducation consists on explaining the functioning of drug use, considering the importance of having information about it to understand the problems and change behaviors ${ }^{5-14}$. Similarly, the debunking of some taboos and beliefs related to drug use assists in the recovery of people. This practice uses communication as the fundamental principle, often only on verbal level, not materializing it in artifacts. Game design may help to propose new psychoeducative experiences, since it works on the tangibilization of immaterial issues, in this case, the information about drug use $^{5,10}$.

In a design perspective, the reference to the experience of learning does not relate to the amount of information acquired or to behavioral changes that may result from it. "Experience" is the quality of the interaction between people and artifacts ${ }^{15}$. Therefore, patients' interactions with their relatives during a family group therapy, e.g., may be more fluid and less stressful, if and when mediated by a game dynamic designed to this end.

Although only a few studies explore this topic in design ${ }^{16,17}$, in the health field, the use of therapeutic games in the treatment of drug use is not a novel topic. Some examples are a body motion-activated videogame developed to opioid relapse prevention among youth ${ }^{16}$ and the "Downward Spital"17, which is a board game that explores the consequences of drug use. The relationship between games and psychoeducation is explored in some studies as follows.

Elias-Lambert et al. ${ }^{18}$, e.g., tested the effectiveness of a substance abuse and relationship violence prevention program (Choices \& Consequences) among adolescents. The program integrated digital technologies and game behavior change techniques. Results suggested that approaches that use interactive methods are superior in preventing substance abuse, when they are compared to traditional methods.

Differently, Khazaal et al. ${ }^{19}$ developed a research with adults, but only tobacco abusers were addressed. The authors tested a board game approach to quit smoking. Results indicated that it increased smoking-cessation rates, in comparison to other approaches.

In Brazil, there are a few initiatives related to the development of games to support the treatment of drug use. None of them are comprehensive psychoeducative tools for adults with a focus in design, but two games with an emphasis in prevention among Brazilian teenagers are known in the scientific community: Game of Choice ${ }^{20}$ and Challenges ${ }^{21}$.

Williams et al. ${ }^{20}$ developed the Game of Choice (Jogo da Escolha) based on cards about diverse aspects of drug use. It also has blank cards, in which players can write their own questions. It is a game focused on young users, aiming to promote the discussion of beliefs they have about the topic and to teach abilities to deal with risk situations. Results indicated that the game is a useful approach to typical core beliefs of young drug users and to promote coping skills in risk situations.

Araújo et al. ${ }^{21}$ developed a game called Challenges (Desafios) for teenagers. It is based on roleplaying-game challenges to train abilities to deal with risk situations. It also addresses beliefs usually related to the idea that drugs are a way to deal with problems. It consists of cards with different contents and tasks (characters, challenges, strategies, and rewards). The authors concluded that it was useful to treat and prevent drug use.

In this sense, an innovative psychoeducative game for adult drug users and their relatives was developed with the support of Hospital Mãe de Deus in Southern Brazil. 
This project enables the simulation of relationships and attitudes of patients and relatives, facilitating interpersonal communication. Besides presenting the development of the game "Step by Step", this research was aimed at understanding the potential of game design to improve experiences with psychoeducation among patients and their families.

The theoretical model used to analyze user appraisals to the game was Appraisals Theor ${ }^{22}$. It provides an evaluation of the connection between designed stimuli (in this case, the game) and the user experience that results from this interaction $^{23-25}$. Appraisals are automatic responses to the following question: "What does this situation means to my well-being?" There are seven appraisal components, or key-questions, to understand experience. They were adapted to the context of game design and summarized in Chart $1^{26}$.

Mapping appraisals that lead to positive experiences with existing artifacts allows professionals to develop new projects with a potential to have similar results ${ }^{27}$. To that end, this research helps researchers to understand appraisal patterns that lead to positive experiences with psychoeducation. The game Step by Step is briefly described in the following session.

\section{Step by step: the game}

Step by Step intends to facilitate the interaction of patients and relatives, and to improve experiences with psychoeducation. In the design of the game, it was carried out an ethnographic research published in a previous study ${ }^{28}$. It was developed with patients and family members in CAPS. A detailed characterization of participants is provided in the next section, in which the research methods are described.

The contents to be addressed in the design of the game were based on definitions extracted from three sources: meetings with the mental health team throughout the process of development of the game ${ }^{28}$, interaction with drug users and their family members in CAPS ${ }^{28}$, and existent literature on psychoeducation ${ }^{5-14}$. To be included in the game, a certain content would have to be identified in the literature and/or in the meetings with the health team, and necessarily observed ${ }^{28}$ in the interactions with patients and families. The following themes and actions were addressed in the game: consequences of relapse, expression of feelings and opinions (e.g., qualities of others, accomplishments of others), main concepts on drug use (e.g., craving), and common stories and situations in the life of patients and their family members. They are explored as follows.

The game consists of a dismountable board, action cards, revealing mask, customizable pawns, and a dice, as shown in Figure 1.

The starting point of the game is called "Treatment Beginning", and the finishing point is "Abstinence". The board colors are intended to transmit the feeling of heading to a healthy place. It was used a darker chromatic pattern at the start of the route. When the player moves, the chromatic standard changes to more cheerful

Chart 1. Seven appraisal components in user experience

\begin{tabular}{|l|l|l|}
\hline \multicolumn{1}{|c|}{ Appraisal components } & \multicolumn{1}{|c|}{ Key relational issue } & \multicolumn{1}{c|}{ Key questions } \\
\hline Motive consistency & $\begin{array}{l}\text { Does this event help me in } \\
\text { attaining my goals and motives? }\end{array}$ & $\begin{array}{l}\text { Does this game help me in attaining my } \\
\text { goals and motives related to the treatment? }\end{array}$ \\
\hline Intrinsic pleasantness & $\begin{array}{l}\text { Is this event pleasant or } \\
\text { enjoyable? }\end{array}$ & $\begin{array}{l}\text { Is this game and/or the gaming process } \\
\text { pleasant or enjoyable? }\end{array}$ \\
\hline Expectation confirmation & $\begin{array}{l}\text { Does this event confirm my } \\
\text { expectations? }\end{array}$ & $\begin{array}{l}\text { Does it confirm the expectations I had } \\
\text { before playing it? }\end{array}$ \\
\hline Standards conformance & $\begin{array}{l}\text { Does this event match with my } \\
\text { social norms and standards? }\end{array}$ & $\begin{array}{l}\text { Does this game match known alternatives } \\
\text { to the same type of treatment? }\end{array}$ \\
\hline Coping potential & $\begin{array}{l}\text { Can I handle or change the } \\
\text { event? }\end{array}$ & $\begin{array}{l}\text { Can I handle or face adversities } \\
\text { encountered when I play the game? }\end{array}$ \\
\hline Agency & $\begin{array}{l}\text { Who (or what) is responsible } \\
\text { for this event? }\end{array}$ & $\begin{array}{l}\text { Who (or what) is responsible for a positive/ } \\
\text { negative outcome, when I play the game? }\end{array}$ \\
\hline Certainty & $\begin{array}{l}\text { How certain am I about the } \\
\text { event? }\end{array}$ & $\begin{array}{l}\text { How certain am I that the game and/or its } \\
\text { content will be useful in the future? }\end{array}$ \\
\hline
\end{tabular}

Source: Adapted from Tonetto and Desmet ${ }^{26}$. 
and bright color tones, in order to convey that they are moving towards abstinence, as shown in Figure 1.

The minimum number of players is four (two patients and two family members) and the maximum is ten (five of each type of participant), plus a health professional as mediator.The game path includes weekdays and weekends. Each day is represented by a space delimited in cube shape, and each row represents four weeks of treatment. In the study site where the game was designed, the average treatment time is six months, reason why the board path has six rows.

The "Relapse" action space is symbolized by the icon "question mark" (Figure 2, top row). Participants roll the dice and, if they get the number 2, they move to the space located outside the path of the game, and they lose a round. If they get the numbers 1 or 3, he/she "Is Clean", remaining in the game. Additionally, when players relapse, they have to create a prevention strategy to be communicated to all participants.

The action spaces "Tell" and "Say" are symbolized by the icons "crown" and "heart holding hands", as can be seen in Figure 2 (top row). The player who gets "Tell" shares a conquest of their relative. The player who gets "Say" indicates two qualities of their family member. The goal of these action spaces is to encourage compliments and display of affection.

All players receive a customizable pawn (Figure 2, center); however, they are a team. Even going alone through the board, there is not a single winner. All participants have to wait for their partner to finalize the path.

The actions of the game are promoted by cards (Figure 2, bottom row). A camouflage mechanism prevents players from reading the responses. There were created two layers of overlapping colors. The correct answer is placed on the two previous layers in light lilac. The only

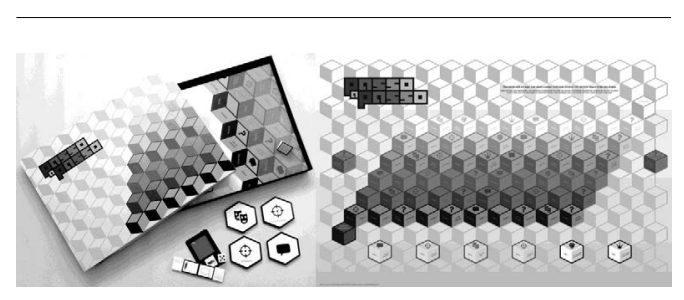

Figure 1. “Step-by-Step” (Basic Components). way to see the answer is using a revealing mask, which stays with the mediator. The actions cards are "Situation", "What is for you", and "Once upon a time".

Represented by the target icon, the "Situation" card contains everyday life events (e.g., A relative asked you money to eat and came back intoxicated. What do you do?). The player who gets in this space takes a card, reads it aloud, and answers it. According to the answer, the mediator will determine their movement on the board. If players give satisfactory responses, they advance one step towards abstinence. If they do not, the mediator has the opportunity to give an appropriate answer. Different "Situation" cards were created to patients and relatives to point out specific problems of each one. It is relevant to highlight that answers to these situations are not predicted in the cards or hidden by camouflage and that mediators must be mental health professionals in order to evaluate if an answer is satisfactory, according to the patient history and treatment evolution.

The "What is for you" card is represented by a balloon talk icon, contains a concept related to psychoeducation (e.g., craving), which the player must describe aloud. Their movement in the

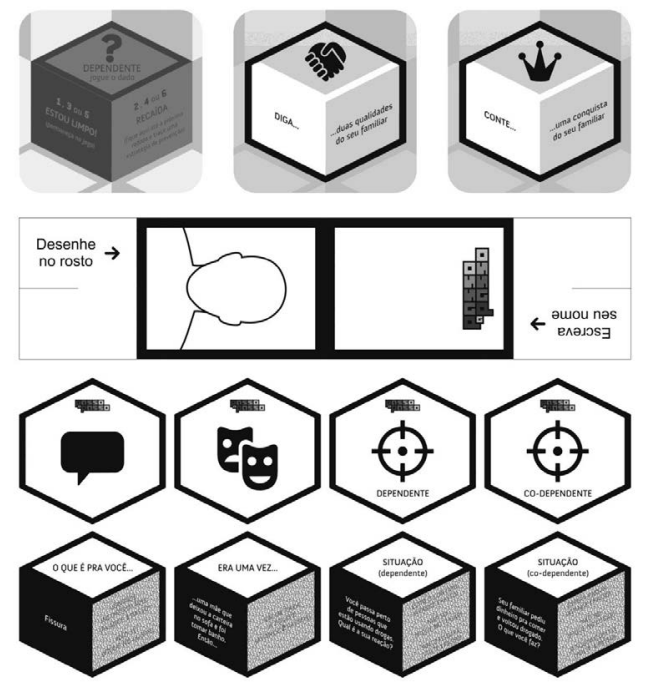

Figure 2. "Step-by-Step": Action Space Relapse (top left), Say (top center), and Tell (top right); Customizable Pawn (central rom); Action Cards (two bottom rows).

Source: Peçaibes et al. ${ }^{28}$. 
game is the same as described in the "Situation" card.

Represented by theater masks, the "Once upon a time" card contains part of a story to be dramatized by the participants, and they create its finale (e.g., a mother left her wallet on the sofa and went to take a shower. So...). It does not have a correct answer. The mediator and the other players will determine the movement of the two pawns on the board. If the team does not have a good performance, the mediator has the opportunity to talk about the subject.

\section{Methods}

An exploratory research was used to understand users' appraisals on the formal aspects of the game (pawn, cards, and board) and the experience (dynamics) of playing it. An ethics committee approved this study, assuring that all procedures followed the Resolution 466/12 $2^{29}$.

Health professionals selected the research participants. They were patients and their family members in treatment at CAPS units, which were regulars of multifamily group meetings. Patients diagnosed with mental retardation and/ or schizophrenia, and those exhibiting signs or symptoms of intoxication by psychoactive substance use were not included in the research. Users who only consumed tobacco were also excluded.

The gaming experience happened during multifamily groups, lasting about one hour. After the sessions, in-depth interviews were carried out and registered in video. Fifteen interviewees took part in the study, as presented in Chart 2. To preserve participants' identities, they are simply indicated as P1 to P15 in the following chapters.

The interview script for this collection was formatted into two sections. The first involved appraisals on the formal elements of the game, and the second aimed to evaluate the experience of the dynamics of playing it. The interviews were analyzed according to the Content Analysis technique.

\section{Results and discussion}

The research results were divided into two subsections: The game and its tangible aspects, and Game dynamics. Categories are highlighted in bold. At the end of each one, there is an appraisal discussion that refers to game design for healthcare.

\section{The game and its tangible aspects}

The game simplicity was exalted by the interviewees and demonstrated that the users quickly understood it and got involved with the platform. Similarly, the familiarity with games indicated that the game language facilitated participants' engagement with the experience, and the analog language configured the board game as inclusive agent:

The game drew attention and was a board... if it were a computer, I believe that few would be willing to... because here we have a group with a lot of age difference. (P6).

Participants stated that they were able to handle the game, helping in the exchange of perceptions and socialization. Therefore, the game was a tactile stimulus that materialized the experience with psychoeducation. The attractiveness of colors, size, and graphic elements were also mentioned, since the game is a visual stimulus:

We got involved there, it caught our attention (...). It is very engaging and stimulating! (P8).

The game rules brought a sense of security, facilitating communication and rapprochement among people:

The advantage is that, as I'm in a game, I am obliged to speak. If my mother have asked me the same question back home, I'd be out or I'd keep quiet. I never had a conversation with my mother about it, only with the game! (P2).

The game instructions enabled overcoming difficulties. Playing it without breaking the rules positively contradicted the patterns of the disease. One of the interviewees mentioned that they had difficulty in understanding the reason to draw the pawn. However, he made it, because he did not want to break a rule. Participants also pointed out the importance of mediation from a professional for a positive experience:

It wasn't tiring because the arbitrator interrupted who was digressing. That doesn't happen in the normal group and it is very annoying. (P2).

Also, new subjects emerged for discussion, avoiding a problem that happens commonly in multifamily groups: the content repetition. In addition to the variety of topics, respondents emphasized that they liked the direct questions in the game cards. They presented easy terms, considering the low level of education of many participants:

It seemed very peaceful. I liked that the questions were direct and short. (P13).

Regarding the action cards, participants indicated that they felt free to build a group response. 
Chart 2. Interviewees' characteristics.

\begin{tabular}{|l|c|c|l|}
\hline \multicolumn{1}{|c|}{ Interviewee } & Gender & Age & \multicolumn{1}{c|}{ Education level } \\
\hline Patient & $\mathrm{M}$ & 26 & Elementary school (complete) \\
\hline Patient (intern) & $\mathrm{M}$ & 30 & Elementary school (complete) \\
\hline Patient & $\mathrm{M}$ & 33 & Elementary school (incomplete) \\
\hline Relative/Mother & $\mathrm{F}$ & 57 & Elementary school (incomplete) \\
\hline Relative/Father & $\mathrm{M}$ & 48 & High school (incomplete) \\
\hline Patient & $\mathrm{M}$ & 47 & Elementary school (incomplete) \\
\hline Relative/Mother & $\mathrm{F}$ & 40 & Elementary school (complete) \\
\hline Patient (intern) & $\mathrm{M}$ & 31 & High school (incomplete) \\
\hline Patient (intern) & $\mathrm{M}$ & 31 & High school (incomplete) \\
\hline Relative/Father & $\mathrm{M}$ & 59 & High school (incomplete) \\
\hline Relative/Mother & $\mathrm{F}$ & 48 & University degree \\
\hline Patient (intern) & $\mathrm{F}$ & 51 & Elementary school (complete) \\
\hline Patient (intern) & $\mathrm{F}$ & 29 & High school (incomplete) \\
\hline Relative/Father & $\mathrm{M}$ & 66 & University degree \\
\hline Relative/Daughter & $\mathrm{F}$ & 24 & University degree (incomplete) \\
\hline
\end{tabular}

Having an answer from a professional provided security to build their answers collaboratively:

I liked the hidden answers thing, because there's a professional response, and we have freedom to say what we think with our words. (P6).

Being able to present themselves safely was important, according to the players. Therefore, the expression of identity and feelings in the customization of the pawns also emerged as a relevant characteristic of the game:

At the moment that you draw, you put your state of mind in that moment. I think that adds to the situation. (P7).

On the other hand, the participation of a family member was seen as unusual. Players shared their experiences with psychoeducation:

Within the rules of the game, I understand $80 \%$. The other $20 \%$ was because there was a relative included. (P3).

It was noteworthy that the tangible elements of the game indicated an appraisal pattern of responses ${ }^{25}$ that seemed to lead to positive experiences: the motives to play the game were consistent, since its characteristics were able to help participants to actually reach their learning goals; some of its elements tend to be pleasurable to use; they break the pattern of learning in a positive way; the expectations users had before playing it were broken, also in a positive way, by being exceeded; the agent to which people attribute the positive experience was the game itself; and users have shown high coping potential to deal with difficulties encountered in playing the game.

\section{Game dynamics}

Participants perceived the atmosphere of the game as an encouraging interface to facilitate communication and rapprochement between patients and their families. The players also pointed out the game dynamics as a positive experience. The guarantee that everyone would expose himself or herself brought to the respondents a sense of security: The game dynamics was great, because everybody participated. Everyone was answering and having fun. Why wouldn't I do it? And it made me relaxed. In normal groups, nobody talks that way. (P1). The interviewees assessed the game as an agent of personal expression, and stated that it promoted equality between patients and relatives, helping in the reduction of prior judgment that they suffer in their relationship: It was safe and peaceful, because everyone is going through what we do. People's judgement, that way, with the game, is not so bad, because we are all equal. (P12). For the interviewees, sharing experiences with others was important to create new strategies to remain abstinent. Yet, the dramatization was a way to experience likely challenges: The acting part was great, because I would never do that in a group. (...) The questions for the family helped them to deal with it. (P10).The experience of playing pointed out the game as a stimulus to be in the treatment. On the interviewees' perception, it made them feel valued: If we had [the game] every time, it would be great. I think it would bring more people, through word-to-mouth. They would 
be interested. And there was a colleague who didn't play and then commented: 'Wow! I wish I had played'. (P1).

The importance of the professionals' feedback was also mentioned. The respondents realized the importance of a mediator, addressing the questions they have. Thus, the game provided a new evaluation perspective about the group therapy, and participants suggested the use of the game as a complement of the existing therapies:

I believe that, if you can address the disease in different ways and add this interesting form of game to the usual meeting [pause], it would be perfect. (P9).

The game dynamics simulated realistic approaches to the subjects:

I thought the relapse was pretty cool. I felt like the times when I relapse, like, when you go to a party and do the wrong thing." (P1).

There is little offer of creative tools for the treatment of drug use, and the innovative approach of the game surprised the interviewees. Consequently, the game promoted standards break on the treatment:

At first I didn't understand what it was. I thought it wouldn't even be a game, because in all my hospitalizations there are always family groups. (P13).

The dynamics of the game indicated an appraisal pattern ${ }^{25}$ that seemed to lead to positive experiences: the motives to play the game were consistent, as also seen in the previous section; some elements of the dynamics tend to be pleasurable to interact with; they break standard ways of trying to learn the same contents; the expectations users had before playing it were met or exceeded; participants indicated to be certain that the dynamics will still be trustable in the future; the agent to which people attribute the positive experience was the game itself, but the player also appeared consistently, different from what was previously described in "tangible aspects of the game"; and users have shown high coping potential to deal with difficulties encountered playing the game.

\section{Discussion}

The therapeutic games identified in the literature had shown significant results ${ }^{16-21}$, mainly in preventing relapse, but none of them discussed how gaming situations can change psychoeducative experiences for the better, in a design perspective. This research tackled the formal elements of a game and the designed dynamics to play it, being able to foster future design in the health field.

This design indicated that the area of mental health has some practices ${ }^{5-14}$ that can be tangibilized in therapeutic games. Through the power of materialization that design feature ${ }^{27}$, the designer can create of artifacts for people's use $\mathrm{e}^{15,22,25,27}$. In the case of "Step by Step", results have shown positive experiences in family group meetings, allowing the game to be used in CAPS units in Brazil.

Initiatives such as the development of "Step by Step" are part of the current movement that privileges relapse prevention and out-of-hospital assistance ${ }^{3,4}$, broadening the possibilities of treatment in CAPS, following the Ordinance GM $224 / 1992^{1}$. Even though the game is successfully spread through Southern Brazil, the experience of a single game cannot give generalizable results, but it can still assist in the development of such type of artifact. Thus, the appraisal analysis revealed that the positive gaming experiences seemed to be related to some patterns of responses, according to appraisal components (identified as follows between parentheses).

The primary goal (motive consistency ${ }^{25}$ ) for users was to have a positive experience during psychoeducation, both in individual and in family levels, and the game was able to help them to achieve their aims. One of the main purposes of psychoeducation is training for real life $e^{5}$, so that players perceived the game as a test to real life, without exaggerations that can shake the confidence and credulity, which involves the tool.

Making the game fun is desirable (intrinsic pleasantness ${ }^{25}$ ), but it is not an aspect of a positive learning experience that needs to be addressed in all gaming situations. Knowing the difference between gaming and playing for fun is crucial for people to put themselves in a position of real learning. The designer should master the knowledge about the kind of ludic platform that will be used for the activity, having in mind that users should to stay alert and involved. In the game, these points were observed in the rules and game dynamics.

Exceeding expectations seemed to be an important ingredient to a positive experience, which is surprising a good way (expectation confirmation ${ }^{25}$ ). In this study, design has enhanced the capabilities of the psychoeducative approach, making it engaging and dynamic. When users started to play the game, the initial expectations were mostly exceeded (e.g., the dramatization was knowledge agent). Design is a materiality agent of immaterial issues. There are certain 
treatments, such as psychoeducation, that can be translated into artefacts that facilitate the understanding of the disease by patients and their relatives. Designers are trained to comprehend the needs of people and design products to help materializing issues that are hard to understand in an abstract way.

When comparing the game to other psychoeducation methods, such as multifamily groups, it was able to break standards in a positive way by offering a richer interface and dynamics than methods such as multifamily group therapy (standards conformance ${ }^{25}$ ). Design innovated in the construction of this tool, in the sense of modifying the objetal surrounding. Therefore, to break standards in a positive way, it seemed crucial to understand users' previous experiences to foster new design in this area.

The game itself $\left(\right.$ agency $\left.^{25}\right)$ is the perceived agent of most of the pleasant events during the gamified psychoeducation, but the user is actively involved in many of them. This result indicates that the characteristics of the game itself seem to be the central elements of the experience. In the therapeutic game context, the designed elements must be harmonious in the physical sense of color, shape, graphics, size and materials, but they also need to be simple and accessible facilitators components. To do this, it should not demand a lot of effort and previous knowledge. In the game, for example, players mentioned that, if it had been presented in a technological platform, the adhesion could have been a lot smaller than it was.

All adverse situations encountered in playing the game were easy to deal with (coping potential $^{25}$ ), what made the process of playing challenging, but not anxiogenic. The uncontrolled anxiety can disrupt the treatment, since substance abusers are not masters in dealing with these emotions. It was also noticed that design provided a conscious language shift, through games, to the psychoeducation. It is known that the health field is complex. Therefore, the designer needs to operate with the game language in order to promote positive experiences, according to the particularities of each case. Drug use can be used as an example, since one of the distinctive features of the disease, understood by the designer, is that patients cannot get too aroused.

Life adequate situations and non-invasive dynamics made it clear to users that the content was certainly useful in the future, and that playing the game is worth repeating (certainty ${ }^{25}$ ). The professional is able to design artefacts that allow rapid adhesion of the patient, by creating physical elements that involve them, in the sense that they are effective- ly participating and not just spectators. Respondents mentioned that the possibility of interacting, drawing and painting were activities that promoted engagement. Thus, they felt more active in the process of learning, which resulted in a positive experience with the game.

Finally, interdisciplinarity helped developing and adding knowledge about the target and the environment in which the designed game is. The interviewees noticed that it contemplated the particularities of drug use, their realities and difficulties, and also realized that experts on the subject developed its content. That helped in the sense of security and trust in the artefact, to the point of being mentioned that this tool could be used in together with conventional therapy.

\section{Conclusions}

The aim of this research was to understand the potential of game design to foster positive experiences with psychoeducation, based on the experience of a game called "Step by Step". Both (a) the formal aspects of the game and (b) the dynamics of playing it were evaluated.

Regarding (a) the formal aspects of the design - visual and tactile stimuli - they were understood by the users as facilitators of the dynamics of psychoeducative experiences. The simplicity of the tool was appraised as helpful, since it enabled the inclusion of different generations in one activity, helping them to interact.

As main results related to (b) the game dynamics, respondents believe there was a positive emotional response towards "Step-by-Step", since people felt involved and safe while playing it. They also indicated that the gaming situation allowed people's immersion in the moment, which facilitated the expression of identity and feelings, and also made it safer to address sensitive issues that are not normally spoken among family members. The subjects covered in the game met the life stories of players, such as the development of new abstinence strategies, and improved interaction among them. The exchange of knowledge through creative dynamics has been pointed out as a remarkable experience. It was also suggested that the breaking of the treatment patterns, addressed by the playful aspect of gaming, encouraged and facilitated dialogue between people. These responses made people more open to learn in a less offensive and lighter way.

The analysis of the experience, based on Appraisals Theory, consists in this study's main 
contribution, allowing researchers to understand how it is possible to materialize an intangible experience, which is psychoeducation, in game design. Therefore, results may be used by designers towards the development of therapeutic games to foster positive experiences among its users.

Experienced mental health professionals should guide the plays. Since some patients had doubts about the nature of the activity, and personal issues are addressed, the professional must know the players beforehand, including family histories.

Non-intoxicated and mostly low educated patients composed the sample. They also not diagnosed with any type of mental retardation and/ or schizophrenia. Therefore, the use of the game with other types of patients should be carefully evaluated. Furthermore, clinic trials are need- ed to understand if the game improves leaning, which was not the aim of this paper.

The limitations of this study are mostly related to the research context. It was developed in a single and peculiar Country, what consequently affected the socio-demographic profile of users. Thus, the research population is biased, taking into account the vastness of contexts in which the game could be played, the cultural differences, and the size of the social problem of drug use. This study, in this sense, may be seen as a way for the future design of guidelines towards the development of new games for mental health treatments. Further research is needed to develop actual design guidelines, and cross-cultural studies are suggested to understand the potential of game design to foster positive experiences with psychoeducation.

\section{Collaborations}

V Peçaibes participated in the conception and design of the study; data collection, analysis and interpretation; drafting the article; and approval of the final version of the paper. LM Tonetto participated in the design of the study; data analysis and interpretation; critical review of the paper; and approval of the final version of the article. I Andretta participated in data analysis and interpretation; critical review of the paper; and approval of the final version of the article. 


\section{References}

1. Brazil. Ordinance No. GM 224 of January 29, 1992. Diário Oficial da União 1992; 29 Jan.

2. Brazil. Law No. 10.2016 of April 6, 2001. Diário Oficial da União 2001; 6 Apr.

3. Ronzani TM, Mota DCB. Políticas de Saúde para a Atenção Integral a Usuários de Drogas. In: Secretaria Nacional de Políticas sobre Drogas (SENAD). Prevenção ao uso indevido de drogas: Capacitação para Conselheiros e Lideranças Comunitárias. Brasília: SENAD; 2011. p. 193-215.

4. Xavier RT, Limberger J, Monteiro J, Andretta I. Políticas Públicas de Atenção aos Usuários de Drogas no Contexto Brasileiro: Revisão Narrativa de Literatura. Pesq Práticas Psicos 2018; 13(1):1-12.

5. Marlatt GA, Gordon J. Relapse Prevention: Maintenance Strategies in the Treatment of Addictive Behaviors. New York: Guilford; 1993.

6. Farina M, Terroso LB, Lopes RMF, Argimon IIL. Importância da Psicoeducação em Grupos de Dependentes Químicos: Relato de Experiência. Aletheia 2013; 42:175-185.

7. Thylstrup B, Schrøder S, Hesse M. Psycho-Education for Substance Use and Antisocial Personality Disorder: A Randomized Trial. BMC Psychiatry 2015; 15:283.

8. Kaminer Y, Burleson J, Goldberger R. Cognitive-Behavioral Coping Skills and Psychoeducation Therapies for Adolescent Substance Abuse. J Nervous Mental Disease 2002; 190(11):737-745.

9. Andretta I, Limberger J, Oliveira MS. Abandono de Tratamento de Adolescentes com Uso Abusivo de Substâncias que Cometeram Ato Infracional. Aletheia 2014; 43-44:116-128.

10. Rangé BP, Marlatt GA. Terapia Cognitivo-Comportamental de Transtornos de Abuso de Álcool e Drogas. Rev Bras Psiq 2008; 30(2):s88-s95.

11. Gür F, Gür GC, Okanlı A. The Effect of the Cognitive-behavioral Model-based Psychoeducation and Exercise Intervention on Quality of Life in Alcohol Use Disorder. Arch Psychiatric Nurs 2016; 31(6):541548.

12. Koc M, Iskender M, Soyer F, Dusunceli B, Colak TS. The Effectiveness of the Psychoeducational Effective Parenting Program Application on Symptoms of Psychoactive Substance Use. Ethno Med 2016; 10(2):206215.

13. Marín-Navarrete R, Tena-Suck A, Pérez-López A, Ambriz-Figueroa AK, Larios-Chávez L, Montes de Oca S. Development of a Psychoeducational Intervention for Community-Based Care Facilities to Substance Use Disorders in Mexico. Int $J$ Mental Health Addiction 2018; 16:588-597.

14. Yeh MY, Tung TH, Horng FF, Sung SC. Effectiveness of a psychoeducational programme in enhancing motivation to change alcohol-addictive behaviour. J Clin Nurs 2017; 26(21-22):3724-3733.

15. Desmet PMA, Hekkert P. Framework of product experience. Int J Design 2007; 1(1):57-66.

16. Abroms LC, Leavitt LE, Van Alstyne JM, Schindler-Ruwisch JM, Fishman MJ, Greenberg D. A Motion Videogame for Opioid Relapse Prevention. Games Health J 2015; 4(6):494-501.
17. Czuchry M, Sia T, Dansereau D. Preventing Alcohol Abuse: An Examination of the "Downward Spiral" Game and Educational Videos. J Drug Education 1999; 29(4):323-335.

18. Elias-Lambert N, Boyas JF, Black BM, Schoech RJ. Preventing substance abuse and relationship violence: Proof-of-concept evaluation of a social, multi-user, tablet-based game. Children Youth Serv Rev 2015; 53:201-210.

19. Khazaal Y, Chatton A, Prezzemolo R, Zebouni F, Edel Y, Jacquet J, Ruggeri O, Burnens E, Monney G, Protti AS, Etter JF, Khan R, Cornuz J, Zullino D. Impact of a board-game approach on current smokers: a randomized controlled trial. Subst Abuse Treat Prev Policy 2013; 8(3):1-14.

20. Williams AV, Meyer EM, Pechansky F. Desenvolvimento de um Jogo Terapêutico para Prevenção da Recaída e Motivação para Mudança em Jovens Usuários de Drogas. Psicol Teoria Pesq 2007; 23(4):407-414.

21. Araújo RB, Oliveira MMA, Cemi AOJ. Desenvolvimento de Role-Playing Game para Prevenção e Tratamento da Dependência de Drogas na Adolescência. Psicol Teoria Pesq 2011; 27(3):347-356.

22. Desmet PMA. Designing Emotions. Delft: Delft University of Technology; 2002.

23. Frijda N. The Emotions. Cambridge: Columbia University Press; 1986.

24. Lazarus RS. Emotional and Adaptation. Oxford: Oxford University Press; 1991.

25. Demir E, Desmet PMA, Hekkert P. Appraisal Patterns of Emotions in Human-Product Interaction. Int J Design 2009; 3(2):41-51.

26. Tonetto LM, Desmet PMA. Why we love or hate our cars: A qualitative approach to the development of a quantitative user experience survey. Applied Ergonomics 2016; 56:68-74.

27. Desmet PMA, Hekkert P. Special Issue Editorial: Design \& Emotion. Int J Design 2009; 3(2):1-6.

28. Peçaibes V, Tonetto LM, Luzzardi HM. Desenvolvimento de um jogo terapêutico para psicoeducação na dependência química. Educ Gráfica 2016; 20(1):76-96.

29. Brazil. Conselho Nacional de Saúde. Resolution No. 466. Diário Oficial da União 2012; 12 Dec.
Article submitted 19/06/2017

Approved 26/09/2018

Final version submitted 28/09/2018 